\title{
Cancer mortality in an Italian rubber factory
}

\author{
L BERNARDINELLI, R DE MARCO, C TINELLI \\ From the Department of Medical Statistics, University of Pavia, Pavia, Italy
}

ABSTRACT The purpose of the study was to describe the mortality experience of an Italian cohort of rubber workers and an attempt was made to identify any occupational cancer hazards that might currently be affecting men employed in this type of work. A total of 4917 male workers who first started working in a large rubber factory between 1962 and 1972 have been followed up until 31 January 1983. The number of deaths from all causes and from malignant neoplasms was determined and compared with the expected number of deaths calculated from mortality rates for the province in which the population of the plant lived. Mortality from all causes was $85 \%$ of that expected. A slight overall excess of deaths from cancer $(S M R=119)$ was found; this was entirely due to the excess mortality in the 35-44 age group. In order further to evaluate the possible existence of a cancer risk SMRs were analysed by duration of exposure, time since first exposure, and for specific sites of cancer. A trend in SMR with duration of exposure was found for employees with 10 years of follow up or more. A high risk for some tumour sites emerged.

It has been observed that workers in the rubber industry have been and still are faced with a wide variety of environmental hazards in the various phases of the complex manufacturing processes.

Case and Hosker showed increased cancer rates in British rubber workers associated with exposure to benzidine, alpha-naphthylamine, and beta naphthylamine. ${ }^{1}$ In particular, the death rate for bladder cancer from 1936 to 1951 was almost double that of the general population. Similar results were found by Davies $^{2}$ in a study carried out in the cable making industry in which rubber was used. ${ }^{2}$ In 1949 all naphthylamines were withdrawn, but benzidine continued to be used in some sections of the industry until $1956 .{ }^{3}$

In subsequent mortality follow up studies in the United Kingdom it was reported that excesses of bladder cancer mortality were virtually confined to workers first employed before $1950 .{ }^{45}$ Parkes's study showed a statistically significant excess of both lung and stomach cancer mortality among men entering the industry after 1 January 1951 . These results were confirmed by Fox's and Baxter's studies carried out on the basis of a census of $\mathbf{3 8 1}$ factories in the United Kingdom. ${ }^{6-8}$

In the United States during the early 1970s epidemiological studies of major rubber manufacturing plants were undertaken by the Department of Epi-

Accepted 5 February 1986 demiology of the Harvard School of Public Health in Boston and by the University of North Carolina. ${ }^{9-18}$ These studies showed more cancer related deaths than expected for bladder, stomach, large intestine, and other sites. Some excesses were found in an entire factory population and others in rubber workers in specific job categories.

This brief review points out that although it has been over 30 years since an excess of bladder cancer was first identified, the fear has persisted that these hazards could still be affecting men working in the industry today. Furthermore, suspicions have also arisen that hitherto unsuspected excesses of other forms of cancer may be occurring.

The purpose of the present study was to describe the mortality experience of an Italian cohort of male rubber workers, and an attempt was made to identify any occupational cancer hazard that might currently be affecting men employed in this industry.

The cohort studied comprised all male workers hired by a large Italian rubber factory from 1962 (the year in which it began operating) to 1972 ; this cohort was followed up until January 1983.

\section{Methods}

DEFINITION OF POPULATION

All members of the study population began working for the same tyre manufacturing company in northern Italy between 1962 and 1972. Since the factory 
opened in 1962 a card has been kept by the company for each employee. Data on the card include name, sex, date of birth, date of first employment, date when employment terminated, date and code of department change, and reasons for termination (death, retirement, left employment).

For the purpose of the study the population was separated into two groups: "office" and "non-office."

Office-Employees who always performed clerical work.

Non-office-Employees who always performed manual labour or who began as manual labourers and were later promoted to clerical or supervisory positions.

\section{FOLLOW UP}

A total of 5424 men employed in the chosen period were identified from the company files but 356 of those who had worked for less than one year were not included; the first study population thus consisted of 5068 workers. Because of the small number of office workers (151) the study was limited principally to the 4917 non-office male subjects. As of January 1983, company records showed the following picture: 3784 active employees, 78 retired, 110 known to have died, and 1096 who had left employment.

The status of each employee who had terminated employment before reaching retirement as well as that of those who had retired was determined from demographic records available in their communities of residence. All subjects, except four who had emigrated, were traced; 33 additional deaths were found both among terminated workers and retirees.

For all of the 143 persons known to have died a copy of the death certificate was requested. Death certificates could not be found for two $(1 \cdot 4 \%)$. The cause of death was coded by a nosologist trained at the Central National Institute of Statistics (ISTAT) according to the International Classification of Diseases (ICD), 8th revision.

\section{STATISTICAL ANALYSIS}

The number of deaths observed was compared with the number of deaths expected using SMRs and relative confidence limits (one sided Poisson test). Deaths expected were computed on the basis of age time cause specific mortality rates for the province in which the factory was situated. Age was divided into five year intervals. Time intervals were: 1962-70, 1971-9, and 1980-2, whereas the reference rates used were respectively: 1971-5, 1971-9, and 1975-9.

The choice of male provincial death rates for reference was supported by the fact that the factory was in a rural province and all members of the study cohort lived nearby. Therefore, the reference population chosen was the closest to the study group with respect to living habits and environmental exposure. In addition, the size of the reference population was large enough to guarantee the stability of the rates which were based on about $220000 \mathrm{men} /$ year.

The use of non-synchronous calendar periods which was necessary because data for certain intervals were not available, did not seem to affect the SMR estimates because no time trend for cancer mortality rates, except for lung cancer, emerged in the 1971-9 period (fig 1). SMRs were examined according to age years since first exposure, duration of exposure, and specific cause of death.

The statistical analysis was performed using the program MANYEARS written by $J$ Peto. We $\omega$ modified the program in order simultaneously to analyse SMRs by duration of exposure and time since first exposure.

\section{Results}

Table 1 classifies the non-office male cohort according 
Table 1 Number of non-office men classified by age on 31 January 1983 or at death, and whether living or dead from 1962 to 1983

\begin{tabular}{lcccc}
\hline Age at 31 January 1983 or at death & Living & Dead & Total living and dead & Person-years at risk \\
\hline $15-24$ & - & 8 & 8 & 6560 \\
$25-34$ & 872 & 26 & 898 & 31566 \\
$35-44$ & 2493 & 31 & 2544 & 23697 \\
$45-54$ & 1246 & 19 & 1282 & 6494 \\
$\geqslant 55$ & 166 & 140 & 4917 & 916 \\
All ages & 4777 & 69233 \\
\hline
\end{tabular}

Table 2 Percentage of cumulative years of employment experience from 1962 to 1972 for all non-office men

\begin{tabular}{|c|c|c|c|c|c|}
\hline \multirow{2}{*}{$\begin{array}{l}\text { Age at } \\
\text { time of } \\
\text { hiring }\end{array}$} & \multicolumn{5}{|c|}{ Cumulative years of employment experience } \\
\hline & All & $I-3$ & $3-7$ & $7-12$ & $>12$ \\
\hline $\begin{array}{l}15-24 \\
25-34 \\
35-44 \\
45-54 \\
\geqslant 55 \\
\text { All ages }\end{array}$ & $\begin{array}{l}100 \cdot 0 \\
100 \cdot 0 \\
100 \cdot 0 \\
100 \cdot 0 \\
100.0 \\
100.0\end{array}$ & $\begin{array}{l}8 \cdot 7 \\
6 \cdot 5 \\
3 \cdot 8 \\
5 \cdot 9 \\
\frac{7 \cdot 1}{7 \cdot 1}\end{array}$ & $\begin{array}{r}11 \cdot 5 \\
7.7 \\
5.8 \\
18 \cdot 4 \\
100 \cdot 0 \\
9.4\end{array}$ & $\begin{array}{l}21 \cdot 4 \\
19 \cdot 6 \\
39 \cdot 6 \\
57 \cdot 3 \\
\overline{23} \cdot 9\end{array}$ & $\begin{array}{l}58 \cdot 4 \\
66 \cdot 2 \\
50 \cdot 8 \\
18 \cdot 4 \\
\frac{59 \cdot 6}{}\end{array}$ \\
\hline
\end{tabular}

Table 3 Observed (O), expected ( $E$ ) deaths, $S M R s$, and confidence intervals for all causes classified by age(non-office men)

\begin{tabular}{lrrrl}
\hline Age & \multicolumn{1}{l}{ O } & \multicolumn{1}{l}{ S } & SMR & $\begin{array}{l}\text { Confidence } \\
\text { interval }\end{array}$ \\
\hline $15-24$ & 8 & 6.99 & 114 & $(49-225)$ \\
$25-34$ & 27 & $39 \cdot 12$ & 69 & $(45-100)$ \\
$35-44$ & 50 & 61.44 & 81 & $(60-107)$ \\
$45-54$ & 33 & 40.48 & 82 & $(55-113)$ \\
$\geqslant 55$ & 19 & 15.8 & 120 & $(72-188)$ \\
Total & 140 & 163.83 & 85 & $(72-101)$ \\
\hline
\end{tabular}

Table 4 Observed $(O)$, expected ( $E$ ) deaths, $S M R s$, and confidence intervals for all neoplasms classified by age (non-office men)

\begin{tabular}{lrrrr}
\hline Age & $O$ & \multicolumn{1}{c}{$E$} & SMR & $\begin{array}{l}\text { Confidence } \\
\text { interval }\end{array}$ \\
\hline $15-24$ & 0 & $0 \cdot 68$ & 0 & - \\
$25-34$ & 3 & $3 \cdot 58$ & 84 & $(17-245)$ \\
$35-44$ & 17 & $10 \cdot 83$ & 157 & $(91-251)$ \\
$45-54$ & 11 & $9 \cdot 76$ & 113 & $(56-202)$ \\
$\geqslant 55$ & 4 & $4 \cdot 49$ & 89 & $(24-228)$ \\
Total & 35 & $29 \cdot 34$ & 119 & $(83-166)$ \\
\hline
\end{tabular}

Table 5 Mortality for all causes (SMRs) by duration of exposure and follow up period in non-office men. (Numbers in parentheses are observed deaths)

\begin{tabular}{lllllll}
\hline $\begin{array}{l}\text { Exposure } \\
\text { (years) }\end{array}$ & \multicolumn{6}{l}{ Follow up period (years) } \\
\cline { 2 - 6 } & $1-5$ & $6-10$ & $11-15$ & $>15$ & Total \\
\hline $1-5$ & $97(47)$ & $116(7)$ & $25(1)$ & $82(1)$ & $94(56)$ \\
$6-10$ & - & $91(48)$ & $141(6)$ & $263(2)$ & $96(56)$ \\
$11-15$ & - & - & $60(21)$ & $0(0)$ & $59(21)$ \\
$>15$ & - & - & - & $64(7)$ & $64(7)$ \\
& $97(47)$ & $93(55)$ & $65(28)$ & $21(10)$ & $85(140)$ \\
\hline
\end{tabular}

to age on 31 January 1983 or at time of death. On the follow up date, $71 \%$ of the cohort was under 45 and $96 \%$ under $55 ; 62 \%$ of deaths occurred among workers in the 35-54 age group. The last column in table 1 shows the person-years at risk for each age group: $89 \%$ of person-years at risk were in the under 44 age group. The office group had 2273 person-years and three deaths. The age distribution did not differ from that of the non-office workers.

Table 2 illustrates the percentage of cumulative years of employment experience for all non-office men employed during 1962-72, classified by age at time of hiring. More than $92 \%$ of the non-office male employees in the company had worked for more than three years during the period of observation.

It may be noted that despite the variations in the extent of cumulative employment experience by age, the employment pattern appears to be stable. For example, $59.6 \%$ of the total non-office male employees worked for more than 12 years in the same factory during the period studied.

The number of observed and expected deaths from all causes for all non-office men classified by age is presented in table 3. The overall SMR for all causes of death was 85 .

Except for the first age group, an increasing trend with age is noted when the age specific SMRs are examined. This is probably due to the healthy worker effect. The higher than expected SMR of the first group is due to an excess of mortality from accidents and suicides; in fact all deaths in the 15-24 age group are due to these causes.

When the overall cancer mortality is considered (table 4) a slight risk excess (SMR = 119) emerges but there is no trend with age. Interestingly, the largest excess, about $50 \%$ more than expected, is recorded in the 35-44 age group. In the office group the SMR for all causes is 40 , whereas the SMR for all cancer (1 death observed) is 65 .

In table 5 SMRs for all causes are presented according to duration of exposure and follow up period. The SMRs along the lower diagonal largely reflect the mortality experience of the active work force: these subjects died no later than five years after they stopped working; many died while still actively employed. 
Table 6 Mortality for cancer (SMRs) by duration of exposure and follow up period in non-office men. (Numbers in parentheses are observed deaths)

\begin{tabular}{llllll}
\hline \multirow{2}{*}{$\begin{array}{l}\text { Exposure } \\
\text { (years) }\end{array}$} & \multicolumn{5}{l}{ Follow up period (years) } \\
\cline { 2 - 6 } & $1-5$ & $6-10$ & $11-15$ & $>15$ & \multicolumn{1}{l}{ Total } \\
\hline $1-5$ & $88(6)$ & $200(2)$ & $0(0)$ & $0(0)$ & $90(8)$ \\
$6-10$ & - & $157(15)$ & $106(1)$ & $0(0)$ & $150(16)$ \\
$11-15$ & - & - & $99(7)$ & $0(0)$ & $95(7)$ \\
$>15$ & - & - & - & $160(4)$ & $160(4)$ \\
& $88(6)$ & $161(17)$ & $91(8)$ & $123(4)$ & $119(35)$ \\
\hline
\end{tabular}

The SMRs along the lower diagonal ranged between 64 and 97 . Fifty per cent of SMRs above the lower diagonal are greater than 100 . This probably reflects the retirement pattern of healthy and unhealthy workers: those who are unhealthy (for any reason) retire and have a higher risk of dying within five to ten years than those who continue to work. This cannot simply be an age phenomenon, since if we take only men aged over 60 the SMRs do not change.

Table 6 shows the SMRs for cancer mortality according to duration of exposure and follow up period. No trend was observed in the SMRs with years since first exposure but this could be due to the rather short follow up period. The SMRs of cancer mortality in the lower diagonal ranged between 88 and 160 . No retirement pattern emerged.

Examining the active work force, two modest excesses of mortality may be seen-one after five years of exposure and the other after 15 years. Looking at the follow up period and duration of exposure it may be seen that in both the excesses fall in the 6-10 and more than 15 years classes. In addition, the data

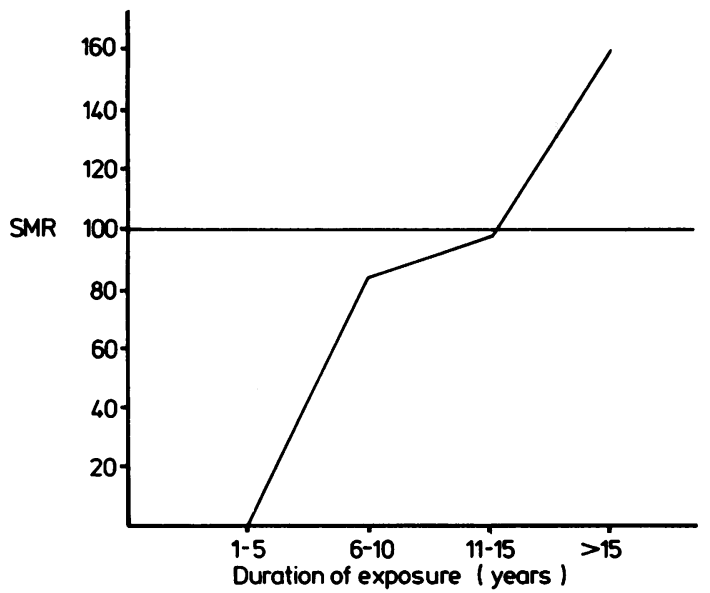

Fig $2 S M R$ by duration of exposure in non-office men with ten or more years of follow' up.
Table 7 SMRs for specific causes (non-office men)

\begin{tabular}{llrc}
\hline Cause of death & Code & Obs & SMR \\
\hline All deaths & & 140 & 85 \\
All malignant neoplasms: & $140-209$ & 35 & 119 \\
Stomach & $151-151.9$ & 6 & 142 \\
Rectum & $154-154.2$ & 1 & 118 \\
Liver & $155-155.1$ & 2 & $517^{*}$ \\
Pancreas & $157-157.9$ & 1 & 80 \\
Peritoneum & $158-158.9$ & 2 & $535^{*}$ \\
Maxillary sinus & $160-160.9$ & 1 & $3735^{*}$ \\
Larynx & $161-161.9$ & 2 & 129 \\
Bronchus, trachea, lung & $162-162.1$ & 4 & 67 \\
Skin & $173-173.9$ & 1 & 635 \\
Prostate & $185-185.0$ & 2 & $518^{*}$ \\
Testicle & $186-186.0$ & 1 & 113 \\
Bladder & $188-188.0$ & 1 & 137 \\
Brain & $191-191.0$ & 2 & 210 \\
Thyroid & $193-193.0$ & 1 & 503 \\
Unspecified neoplasms & $195-199.1$ & 3 & 198 \\
Hodgkin & $201-202.9$ & 2 & 168 \\
Myeloid leukaemia & $205-205.9$ & 2 & 359 \\
Other leukaemia & $207-207.9$ & 1 & 114 \\
Circulatory system & $390-458.9$ & 25 & 63 \\
Coronary heart disease & $410-414.9$ & 14 & 67 \\
Respiratory system & $460-519.9$ & - & - \\
Digestive system & $520-577.9$ & 12 & 61 \\
Genitourinary system & $580-629.9$ & 5 & 172 \\
Accidents & $800-999.9$ & 52 & 125 \\
Suicides & $950-959.9$ & 11 & 109 \\
\hline D & & &
\end{tabular}

${ }^{*} \mathrm{p}<0.05$ (one sided Poisson test).

showed a weak trend of SMRs with duration of exposure after ten years of follow up (fig 2).

Table 7 gives the SMRs for selected cancer sites and other specific causes of death. The highest cancer SMRs recorded in this factory were for the following cancers: maxillary sinus (3735), skin (635), peritoneum (535), prostate (518), liver (517), thyroid (503), and myeloid leukaemia (359).

The following SMRs were found to be statistically significant (one sided Poisson test): liver, peritoneum, maxillary sinus, and prostate.

\section{Discussion}

Several features of this study must be taken into account when evaluating the results. The first concerns the follow up period. Since the factory opened in 1962, the follow up period available is necessarily short: on average 14 years. Consequently the probability of observing deaths is lower than would be expected with a longer follow up period, especially for of deaths from cancer whose latent period is known to $N$ be 15-20 years. As a result an underestimate of SMR is likely to arise.

Another serious problem in our study has been the dilution factor in terms of the use of the total nonoffice male population of the plant as the cohort. In fact, there may be multiple types of exposure. The toxicological effects would have to be overwhelming, however, to change the mortality pattern of the total population of the cohort, whereas the impact could be 
detected in a specific department if such changes in mortality for specific causes did occur. A broad comparison between exposed (non-office) and nonexposed (office personnel) groups inside the factory showed that the risk for cancer was doubled in the exposed group, although the number of non-exposed subjects was too small to make the result reliable.

In addition, a central issue in mortality studies among occupational groups is the choice of a comparison group. The best type of comparison group would be a group of workers similar to the group under study in every respect except exposure to the agent of interest. Unfortunately, such controls are usually impossible to find and comparison must be made with the general population. In this study male provincial deaths rates were used because they are the more suitable in terms of comparability with the study cohort and the most readily available in sufficient cause age time specific details.

In studies of mortality when expected deaths are computed using death rates for some general population, SMRs less than 100 are common because most employed people are relatively healthy. This effect is inversely proportional to the age of the group being studied.

Thus for the reasons described any SMR from this study is likely to be an underestimate of the true SMR in the total population of rubber workers. Therefore the SMR from all causes of death of 85 is not surprising. It is interesting to note, however, that despite all the sources of underestimation, the SMR from all cancer deaths is 119 . When the SMRs are analysed in each age group a greater excess emerges in the 35-44 age group. The SMRs computed for this age group are based on the largest number of observed deaths and thus are most stable, as may be seen from the relative confidence limits.

No relation was found between mortality risk for all causes and years since first exposure and between the former and duration of exposure; this could be due to the short follow up period. There was a trend of cancer risk with duration of exposure. This was weak and could be seen only after ten years of follow up. A dose response relation, if it exists, has a greater chance of detection-after a long follow up period.

The two excesses of cancer risk in the active work force which may be seen respectively after five and 15 years of exposure are difficult to interpret and we believe that a more detailed qualitative and quantitative analysis of the data should be carried out.

When examining risks for specific sites of cancer among the cohort of rubber workers, some excesses of mortality were found. Our study confirms results already reported regarding the risks for maxillary sinus and prostate cancer. In addition risks for skin, peritoneum, liver, and thyroid cancer emerged. Myeloid leukaemia with an SMR of 359, although not statistically significant, agrees with data reported by other authors.

Thus an association that has to be further investigated between working in this rubber factory and cancer mortality seems to emerge from our study. The shortness of the latent period, 10 years on average, and the consequent low number of deaths, however, makes it difficult to judge whether this association is causal or not.

We thank Professor R Saracci and Dr N Charnay, International Agency for Research on Cancer, Lyon, for their helpful suggestions and support.

This research was partially supported by Ministero Pubblica Istruzione.

\section{References}

1 Case RAM, Hosker ME. Tumour of the urinary bladder as an occupational disease in the rubber industry in England and Wales. Br J Ind Med 1954;8:39-50.

2 Davies JM. Bladder tumours in the electric cable industry. Lancet 1965;ii:143-6.

3 Parkes G. Cancer research. Lancet 1964;ii:254-5.

4 Veys CA. Bladder cancer in rubber workers: the story reviewed and up-dated. Plastics and Rubber Processing and Applications 1981:1:207-12.

5 Parkes AC, Veys CA, Waterhouse JAH, Peters A. Cancer inortality in the British rubber industry. $\mathrm{Br} J$ Ind Med 1982;39:209-20.

6 Fox AJ, Lindars DC, Owen R. A survey of occupational cancer in the rubber and cablemaking industries: results of five years analysis. 1967-71. Br J Ind Med 1974;31:140-51.

7 Fox AJ, Collier PF. A survey of occupational cancer in the rubber and cablemaking industries: analysis of deaths occurring in 1972-74. Br J Ind Med 1976;33:249-64.

8 Baxter PJ, Werner JB. Mortality in the British rubber industries 1967-76. London: HMSO, 1980.

9 Monson RR, Nakano KK. Mortality among rubber workers. Am $J$ Epidemiol 1976;103:284-303.

10 Monson RR, Fine LJ. Cancer mortality and morbidity among rubber workers. J Natl Cancer Inst 1978;61:1047-53.

11 Fine LJ, Peters JM, Monson RR, Burgess WA. An industrial epidemiology. Chemtech 1980;10:298-301.

12 McMichael AJ, Andjelkovich D, Tyroler HA. Cancer mortality among rubber workers: an epidemiologic study. Ann $N Y$ Acad Sci 1976;271:125-37

13 McMichael AJ, Spirtas R, Gamble JF, Tousey PM. Mortality among rubber workers: relationship to specific jobs. $J$ Occup Med 1976;18:178-85.

14 McMichael AJ, Spirtas R, Kupper LL, Gamble JF. Solvent exposure and leukaemia among rubber workers. J Occup Med 1975; 17:234-9.

15 McMichael AJ, Spirtas R, Kupper LL. An epidemiologic study of mortality within a cohort of rubber workers 1964-72. J Occup Med 1974;16:458-64.

16 Andjelkovich D, Taulbee J, Symons M. Mortality experience of a cohort of rubber workers 1964-73. J Occup Med 1976;18:387-94.

17 Andjelkovich D, Taulbee J, Symons M, Williams T. Mortality of rubber workers with reference to work experience. J Occup Med 1977;19:397-405.

18 Goldsmith DF, Smith AH, McMichael AJ. A case-control study of prostate cancer within a cohort of rubber and tyre workers. J Occup Med 1980;22:533-44. 